\title{
POSSIBILITIES OF DRAINAGE By MECHANICAL MEANS IN NORTHLAND
}

By D. F. SCOTT, Machinery Instructor, Department of Agriculture. Auckland.

Progress in any industry is accelerated by the availability of suitable machinery to do the work. Farming, and particularly farm drainage, is no exception. I would suggest that with the increasing availability of such drainage machinery as this paper mentions, there are great possibilities for farm drainage in Northland. In fact, the stage is set for rapid improvements in farm drainage, which offer great opportunities for increasing production. This applies not only on what is now undeveloped land, but also, and to a far greater extent, on land that is being farmed today and is already cleared, fenced, and supplied with the necessary buildings. There is a big future for mechanised farm drainage in North Auckland, partly because there is no alternative if farming is to be fully developed, and partly because of the recent developments in machinery to do this work. Because-of-the-large-areas-involaed,-there is no possibility of doing the work by hand, so machinery offers. the only solution.

In the past infield drainage has been considered largely a job for the autumn. This is understandable for a number! of reasons. Other work is slacker then, soil is moist and easier to dig by hand, and there is usually some water present as an aid to grading. However, where machines are available there are good reasons why wet conditions, particularly the wettest part of the winter, should be avoided. With machinery hardness_of the_soil for digging is not: usually a major problem. Tiles can be laid more accurately under dry conditions and the usual difficulties associated with working machinery in mud are avoided. Back filling of trenches dug in dry soil is a simple matter, but if the same soil is wet, much time can be spent and the 
resultant job is often very rough. In, some soils tile drainage under wet conditions can result, in joints between the tiles becoming blocked $>$ whereas. under dry conditions this is considerably reduced; There are other great differences between dry weather work by machinery and winter work by hand. Hand work is often done without the use of levels, provided there is a reasonable fall available and there is water to aid the final grading operations, but where the available fall is limited it is possible to dig accurately to a flatter grade when working from levels and using boning, rods than it is when grading with water alone. Hand drainage at great depths is not practicable, but machines can work to a depth of 8,9 , or even $12 \mathrm{ft}$. where necessary, and this one fact opens up possibilities in the drainage of fairly porous soils by deep, widely spaced drains. Machinery will allow extensive schemes to be undertaken because of greatly increased output. The drainage by hand of even a small paddock may take weeks of work; a similar job done mechanically may take only a day. Mechanical drainage, however, brings its problems. The large work output of a modern machine which must be maintained if the machine is to pay for itself means that somebody must be working well ahead in arranging, planning, and setting out the work to be done. It is not just a matter of taking the machine on to a farm and getting to work. In fact, often the biggest part of the job is done before the machine arrives on the farm. If large-scale mechanical drainage work is to be done in---Northland-or-anywhere else, this problemmust be solved, and suggestions $\overline{\text { regarding means of }}$ dealing with it will be discussed later by Professor Hudson.

A modern, fast-cutting tile trench machine working full time requires the services of 1 to 2 men on survey and planning work alone. If such a machine is permitted. to run wild, the results can be disastrous, not only for the farmer whose money is paying for the tiles and the operation of the machine, but also for the contractor or owner, who will very quickly find-that-he-hasdug-himselfrigkt_out of work. Many large areas of land in Northland are already supplied with main drainage schemes but lack infield drains. There is machinery available for this work, but men must be trained to operate the machines and do the planning work ahead,, and also supplies of tiles must be 
arranged. Where large, flattish areas with soil free from shingle or other underground obstacles require 'draining, rotary diggers of the Roteho type excel.

\section{ROTARY DIGGERS}

These machines dig a fairly narrow, straight-sided trench of medium depth to an accurate predetermined grade and suitable for the immediate laying of tiles. . The cutting speeds are high, even up to 15 or 20 chains per hour, but with an average of something like 4 or 5. Because of their size and weight they cannot economically be employed on small jobs. They require a transporter or at least .a heavy truck and loading facilities and they cannot be used where depths greater than about $3 \mathrm{ft}$. 6in. are required or where the soil contains stones, timber, or any other obstacles, and, as mentioned before, they require trained operators who understand: levels and grades and can work from grade pegs set by planning technicians. The organisation required to operate such machines effectively will be discussed by Mr Bowler.

\section{HYDRAULIC BACK-ACTERS}

As an alternative to these rotary diggers there is the relatively new and light hydraulically operated power shovel type of machine, some tractor-mounted and some trailer types. Those machines, although they have a slower cutting speed, are extremely versatile. They can dig to a maximum depth of 8.or $9 \mathrm{ft}$. and can work in soils that would be impossible for rotary diggers. Their bucket size is variable according to the size of trench required, and machines of this type fitted with a $12 \mathrm{in}$. bucket can dig tile trenches 3 to $4 \mathrm{ft}$. deep at the rate of approximately 1 chain per hour. These machines do not grade in one operation as the previous ones, but require a man using a shovel or finishing scoop to follow the machine and adjust final grades according to boning rods. However, with a good operator the duties of this man are not heavy, as he merely has to remove any roughnesses in the bottom of the trench or perhaps the last inch or two to the correct grade. It is likely that machines of this type have a bigger future in the north than rotary diggers, because they are extremely mobile and can be pulled behind a truck or tractor at quite a reasonable speed and also because of their 
versatility. The fact that they can be used to dig: open drains or even for loading or excavating work makes them more attractive. With these machines. the need for planning and level work still applies, and although, because of the slower cutting speed, one technician could possibly service two machines, the danger of working according to the whims of an untrained operator cannot be overstressed.

\section{DRAIN CLEANING}

Further adaptations of this type of machine are' becoming available for cleaning and redigging of existing open' drains, a job which has been calling for new machinery for many years past.

Recently built machines of this type follow several. different designs, but as long as they are operated by a careful man, their future in cleaning the many miles of existing open drains in the north would' seem assured for many years until, perhaps, with the progress we hope for, many of these open drains are replaced by permanent tile drains.

\section{DRAGLINE EXCAVATORS}

In the past we have become familiar with excavators of the dragline type, These machines will always have a use in the digging and cleaning of the larger outlet drains or canals and other work such as straightening and cleaning creek beds.

The back-hoe version of this machine has proved very-good for digging larger open drains and a further

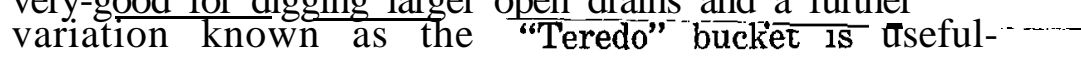
for digging tile drains. The "Teredo" bucket is designed to give a level cut along the bottom of the trench. It can be fitted with a device to give a grooved bottom to fit the tiles and is available in either 8 or 12in. sizes. Either of these buckets has a maximum depth of $4 \mathrm{ft}$. The application. of this type of machine would be more on problem soils which, because of ironstone or cemented layers, cannot be cut by lighter machines. The dragline can work very efficiently on small drains, both cleaning and digging, if fitted w i t h what is known as a- side-arm-attachment. -This attachment allows the dragline to pull its bucket directly along the line of the drain it is digging or cleaning without slewing the machine to do so. A variety of shapes and sizes of buckets was made to 
go with. the side arm. However, to. date this attachment has not been very common in New 'Zealand and nowadays, with the advent of the lighter hydraulically operated diggers and the dragline's high initial cost, its weight and transport difficulties between farms will compel it to be used mainly for the larger drains mentioned earlier.

For a large drainage organisation two machines, the rotary digger and the hydraulically operated shovel? make an excellent combination, but here again the digging power is likely to exceed the planning power of most organisations and it seems that to allow this to occur is likely to be serious for operators doing drainage work.

As well as the machinery mentioned so far, there is quite an assortment of other types available. The chain type of trencher has become quite a common sight on trenching jobs, particularly about Auckland. These machines have a reasonable digging speed up to a maximum of 4 or 5 chains per hour. Some can travel on the road at quite high speeds and their maximum digging depth of $6 \mathrm{ft}$. makes them attractive. They have, however, a number of weaknesses which make them rather unsuitable for farm drainage work. Their ability to cut to an accurate grade is limited by the fact that they are supported by small wheels and the vehicle is sprung. These factors make it difficult for the operator to grade accurately on anything like a soft or bumpy surface. There is also difficulty with the attachment of a grading device which is consistently accurate over the machine's, full digging range. However, these disadvantages have not prevented altogether their use on farms, but in my opinion anyway they are better equipped for the work in which most of them are now engaged, that of cable and pipe laying about the cities.

\section{LARGE. BOOM-TYPE DIGGERS}

A few models of a large 'American ditcher have been imported to New Zealand. These machines have the ability to dig both tide and deep, trenches at fairly fast speeds. The machines are mounted either on tracks or on rubber tyres and can cut a great variety of difficult soils. They have, however, a number of apparent disadvantages, the greatest probably being the initial cost of about $\$ 6000$. Their size and weight, from the point of view of transport, also detract from 
their usefulness on farm work. Their ability to cut at high speeds would make it imperative for them to have an efficient survey and planning team working with them. Once again with this machine I feel that its scope lies more in the industrial field.

\section{ROAD GRADER}

The modern road grader which is familiar to all of us can be used to great advantage on farm drainage work. Its use is restricted, however, to dry weather, but if conditions are right, it can do .a lot of work in a short time. Its uses are digging drains for tiles, levelling work prior to drainage, removing spoil along the banks of existing open drains, and even for surface drainage where conditions of outlet make it necessary to use that drainage method. The importance of land levelling in drainage work cannot be overstressed ; whether the work is done by graders as mentioned above or by less powerful and slower machines more in the range of the farmer's own equipment is immaterial.

\section{JOHNS' LEVELLER}

An extremely useful piece of equipment which any farmer can own is the "Johns' Leveller". This implement can easily be made in any farm workshop and if used when a paddock is under cultivation and has a considerable tilth it can greatly improve surface conditions. This machine is particularly useful where it is intended to mole drain the paddock once it is established in pasture, and the value of a level surface for this work makes-it-a-payable-proposition-for. extra cultivation and considerable time to be spent in the. levelling process. Another machine which is probably equally effective can be made from two lengths of railway line about $12 \mathrm{ft}$. long and spaced about $2 \mathrm{ft}$. apart. These are mounted on the hydraulic lift of a tractor and have the advantage that only one man, the tractor driver, is needed.

\section{SIMPLE DITCH-CUTTING DEVICES}

An example of simple machines which can be used to dig trenches for tiles is the "Linton" drainer. - It employs a U-shaped cutter and an inclined plane or ramp along which the spoil from the cutter slides to the surface. These machines can be drawn either by a crawler or large wheel tractor and are pulled 
several times along the line of the proposed drain, taking out cuts from 4 to $6 \mathrm{in}$. deep on each run. No hand grading would be necessary where falls were obvious and continuous, but where grading is necessary this can be done either by hand on the. bottom of the finished trench or if a bulldozer is available it is possible to grade the surface along the drain line prior to commencing the drainage work.

With all the machines mentioned above, excepting the road grader, some other means must be provided for back filling the trenches. The makers of the one machine supply a light angle-dozer blade which can be mounted -either on the machine itself or on some other vehicle which has sufficient power and traction to do. the work. A suitable vehicle would be an ordinary farm tractor or a heavy 4-wheel drive army vehicle. The ease with which back filling work is done depends on weather conditions. It is good practice to back fill each afternoon the trench that is dug that day. This means that rain overnight will not wet and consolidate the spoil and make it very much more difficult to return in a tidy condition,

Back filling can be done with the grader blade mounted on the rear of a tractor fairly satisfactorily, but the angle-dozer on the front performs the job more quickly and with less risk of the tractor sliding into the drain.

This list of machinery shows the great variety of types available for farm drainage work. In Northland the need is obvious and as the work is there and machinery is available to do it, what is now needed is some satisfactory arrangement for operating the machinery and a supply of tiles. Then the possibilities of drainage in Northland by mechanical means are almost unlimited. 